the assessment and management of pain was vague and no detail was given as to how health professionals should perform these tasks. There was no reference to pain intensity, location or emotion. There were several problematic conceptual issues in the way pain was presented, with pain mostly portrayed either in the context of inflammatory or non-inflammatory pain and rarely in the context of both. Musculoskeletal pain was also positioned as a 'somatic' symptom, potentially conveying an interpretation of pain as being psychologically mediated. Conclusion: Training for healthcare professionals in paediatric rheumatology would benefit from updates informed by contemporary pain theories and evidence-based practices. This is key to ensuring that children and young people with chronic pain receive effective pain care from tertiary care services focused on treating musculoskeletal disease.

Table 1. Documents and pain terms identified

\begin{tabular}{|c|c|c|c|}
\hline Profession & Title & $\begin{array}{l}\text { Organisations, } \\
\text { year. }\end{array}$ & $\begin{array}{l}\% \text { of document } \\
\text { covered by } \\
\text { pain terms }\end{array}$ \\
\hline $\begin{array}{l}\text { Doctors } \\
\text { Doctors } \\
\text { Doctors } \\
\text { Doctors } \\
\text { Doctors }\end{array}$ & $\begin{array}{l}\text { Generic syllabus level } 1 . \\
\text { Generic syllabus level } 2 \text {. } \\
\text { Generic syllabus level } 3 \text {. } \\
\text { Paediatric rheumatology level } 3 \text {. } \\
\text { Competencies for the special interest mod- } \\
\quad \text { ule in paediatric rheumatology }\end{array}$ & $\begin{array}{l}\text { RCPCH, } 2018 . \\
\text { RCPCH, } 2018 . \\
\text { RCPCH, } 2018 . \\
\text { RCPCH, } 2018 . \\
\text { RCPCH, } 2014 .\end{array}$ & $\begin{array}{l}0.14 \% \\
0.14 \% \\
0.06 \% \\
0.48 \% \\
0.43 \%\end{array}$ \\
\hline $\begin{array}{l}\text { Nurses } \\
\text { Nurses }\end{array}$ & $\begin{array}{l}\text { Competencies for rheumatology nurses. } \\
\text { Competencies for clinical nurse specialists/ } \\
\text { advanced nurse practitioners. }\end{array}$ & $\begin{array}{l}\text { RCN, } 2020 . \\
\text { BSPAR, } 2014 .\end{array}$ & $\begin{array}{l}0.05 \% \\
0.29 \%\end{array}$ \\
\hline $\begin{array}{l}\text { Nurses } \\
\text { Allied Health } \\
\text { Professionals } \\
\text { (AHPs) }\end{array}$ & $\begin{array}{l}\text { Role of the paediatric rheumatology nurse. } \\
\text { Competencies for AHPs }\end{array}$ & $\begin{array}{l}\text { SPARN, } 2016 . \\
\text { BSPAR, } 2019 .\end{array}$ & $\begin{array}{l}0 \% \\
0.73 \%\end{array}$ \\
\hline
\end{tabular}

Disclosure of Interests: None declared

DOI: 10.1136/annrheumdis-2021-eular.210

\section{POS1491-HPR MENTAL HEALTH OUTCOMES AMONG HEALTH CARE WORKERS DURING THE CORONAVIRUS-19 PANDEMIC}

O. Hamdi ${ }^{1}$, M. Sellami ${ }^{1}$, S. Miladi ${ }^{1}$, A. Fazaa ${ }^{1}$, L. Souabni ${ }^{1}$, K. Ouenniche $^{1}$, S. Kassab ${ }^{1}$, S. Chekilii', K. Ben Abdelghani ${ }^{1}$, A. Laatar ${ }^{1} .{ }^{1}$ Mongi Slim Hospital, Rheumatology, Tunisia, Tunisia

Background: The coronavirus-19 (COVID-19) pandemic is having negative effects on societies' mental health, particularly health care workers who are exposed to tremendous psychological stress.

Objectives: To assess the magnitude of mental health outcomes among health care workers treating patients exposed to COVID-19.

Methods: This cross-sectional study collected demographic data and mental health measurements from health workers in different hospitals using an online questionnaire. Participants were also asked to complete the 9-item Patient Health Questionnaire (PHQ-9), the 7-item Insomnia Severity Index (ISI), and the 7-item Generalized Anxiety Disorder scale (GAD-7). The total scores of these measurement tools were interpreted as follows: PHQ-9 normal (0-4), mild (5-9), moderate (10-14), and severe (15-21) depression; ISI normal (0-7), mild (8-14), moderate (15-21), and severe (22-28) insomnia; GAD-7 normal (0-4), mild (5-9), moderate (10-14), and severe (15-21) anxiety.

Results: A total of 155 health care workers with a mean age of $31.3 \pm 25$ years [26-45] and a sex-ratio of 0.3 completed the online questionnaire. All participants were directly engaged in diagnosing, treating, or caring for patients with or suspected to have COVID-19. Participants were divided into two groups: $79 \%$ medical $61 \%$ doctors in training and $18 \%$ hospital doctors) and $21 \%$ paramedical staff. Twenty-two participants (14.2\%) had a chronic disease and $21(13.5 \%)$ had a history of depression. Nineteen (12.2\%) of the participants were infected with COVID-19, 4 of whom contracted the infection in the hospital $50 \%$ during October 2020). A statement to the department of occupational medicine was made in $70 \%$ of cases. Ninety-one percent of the participants were fit for treating patients with COVID-19. The mean number of nightshifts in the COVID unit per month was 5.3. The mean number of hours of work in the COVID unit was 5 hours per day, 36 hours per week, and 62 hours per month. An increase in workload compared to the pre-epidemic was noted in $62.9 \%$ of cases. Thirteen percent of participants experienced the same anxiety level as the first time of taking care of COVID patients while $65 \%$ were rather at ease compared to the first time. Forty-seven percent of participants felt the need for psychological support and $16.7 \%$ of whom had consulted a psychiatrist. Participants were diagnosed with depression (9 cases), anxiety (13 cases), and burn-out ( 3 cases). The prescribed treatment was: antidepressants (5 cases), anxiolytic (10 cases), and psychotherapy (12 cases). Mild depression was detected in $13 \%$ of cases, moderate depression in $4 \%$ of cases, and severe depression in $2 \%$ of cases. Mild insomnia was detected in $41 \%$ of cases, moderate insomnia in $14 \%$ of cases, and severe insomnia in $9 \%$ of cases. As for anxiety, $33 \%$ of participants suffered from mild anxiety, $14 \%$ moderate anxiety, and $5 \%$ severe anxiety.

Conclusion: Participants reported experiencing psychological burden and a high rate of anxiety, depression, and insomnia. It is important to protect health care workers and to promote mental well-being to survive this pandemic.

Disclosure of Interests: None declared

DOI: 10.1136/annrheumdis-2021-eular.783

\title{
POS1492-HPR EVALUATION OF A VIRTUAL REALITY-BASED APPLICATION TO EDUCATE HEALTHCARE PROFESSIONALS AND MEDICAL STUDENTS ABOUT INFLAMMATORY ARTHRITIS
}

P. Klemm 1 , A. Kleyer ${ }^{2}$, K. Tascilar², L. Schuster ${ }^{2}$, T. Meinderink², F. Steiger ${ }^{2}$, U. Lange ${ }^{1}$, U. Müller-Ladner ${ }^{1}$, J. Knitza ${ }^{2}$, P. Sewerin ${ }^{3}$, J. Mucke ${ }^{3}$, A. Pfeil ${ }^{4}$, G. Schett ${ }^{2}$, F. Hartmann ${ }^{2}$, A. Hueber ${ }^{5}$, D. Simon ${ }^{2}{ }^{1}{ }^{3}$ Justus-Liebig University Gießen, Campus Kerckhoff, Department of Rheumatology, Immunology, Osteology and Physical Medicine, Gießen, Germany; ${ }^{2}$ Universitätsklinikum Erlangen, Department of Internal Medicine 3, Rheumatology and Immunology, Erlangen, Germany, Erlangen, Germany; ${ }^{3}$ Heinrich Heine University Düsseldorf, Department and Hiller Research Unit for Rheumatology, Düsseldorf, Germany; ${ }^{4}$ Jena University Hospital - Friedrich Schiller University, Department of Internal Medicine 3, Jena, Germany; ${ }^{5}$ Sozialstiftung Bamberg, Sektion Rheumatologie, Bamberg, Germany

Background: Inflammatory arthritides (IA), such as rheumatoid arthritis or psoriatic arthritis, are disorders that can be difficult to comprehend for health professionals and students in terms of the heterogeneity of clinical symptoms and pathologies. New didactic approaches using innovative technologies such as Virtual Reality (VR) applications could be helpful to demonstrate disease manifestations as well as joint pathologies in a more comprehensive way. However the potential of using a VR education concept in IA has not yet been evaluated. Objectives: We evaluated the feasibility of a VR application to educate healthcare professionals and medical students about IA.

Methods: We developed a VR application using IA patients data as well as two- and three-dimensional visualized pathological joints from X-ray and computed tomography generated images (1). This VR application (called Rheumality) allows the user to interact with representative arthritic joint and bone pathologies of IA patients (Figure $1 \mathrm{~A}, \mathrm{~B}$ ). In a consensus meeting an online questionnaire was designed to collect basic demographic data (age, sex), profession of the participants, and their feedback on the general impression, knowledge gain and potential areas of application of the VR application. The VR application was subsequently tested and evaluated by healthcare professionals (physicians, researchers, and other healthcare professionals) and medical students at predefined events (two annual rheumatology conferences and academic teaching seminars at two sites in Germany). Results: 125 individuals participated in this study (56\% female, $43 \%$ male, $1 \%$ non-binary). $59 \%$ of the participants were between $18-30$ years of age, $18 \%$ between $31-40$, $10 \%$ between $41-50,8 \%$ between $51-60$ and $5 \%$ were between $61-70$. Of the participants, 50 were physicians, five researchers and four other health care professionals, the remaining were medical students (66). The participants rated the application as excellent (Figure 1 C, D), the mean rating of the VR application was 9.0/10 (SD 1.2) and many participants would recommend the use of the application, with a mean recommendation score of 3.2/4 (SD 1.1). A large majority stated that the presentation of pathological bone formation improves the understanding of the disease (120 out of $125(96 \%))$.

Conclusion: The data show that IA-targeting innovative teaching approaches based on VR technology are feasible. The use of VR applications enables a disease-specific knowledge visualization and may add a new educational pillar to conventional educational approaches.

REFERENCES:

[1] Kleyer A et al. Z Rheumatol 78, 112-115 (2019)

A
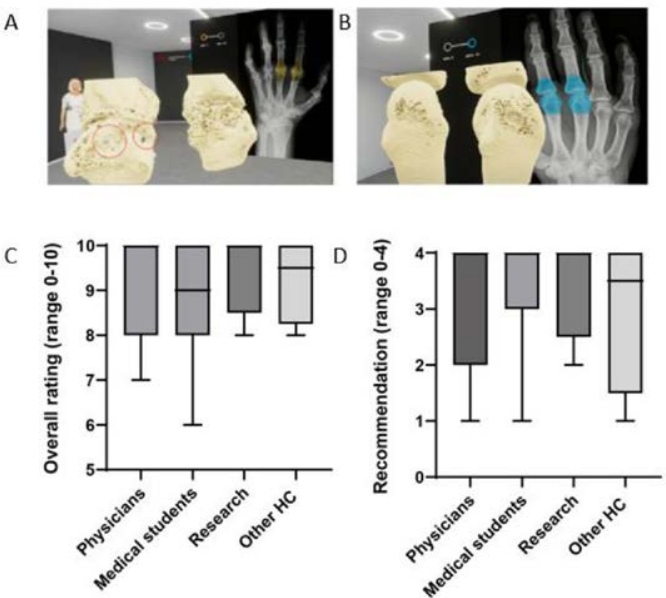

Figure 1. Illustration of the VR application and evaluation results 